\title{
Means of Knowledge Dissemination: Are the Café Scientifique and the Artistic Performance Equally Effective?
}

\author{
Darquise Lafrenière ${ }^{1}$, Susan M. Cox ${ }^{2}$ \\ ${ }^{1}$ Department of Social and Preventive Medicine, University of Montreal, Montreal, Canada \\ ${ }^{2}$ W. Maurice Young Centre for Applied Ethics, University of British Columbia, Vancouver, Canada \\ Email: darquise.lafreniere@umontreal.ca, suecox@exchange.ubc.ca
}

Received December $17^{\text {th }}, 2011$; revised January $25^{\text {th }}, 2012$; accepted February $19^{\text {th }}, 2012$

\begin{abstract}
An increasing number of health researchers are opting for innovative approaches to communicate research findings. This article compares two methods for disseminating findings to various audiences: the Café Scientifique and the artistic performance. Analysis of surveys completed by 78 respondents indicates that the artistic performance is more effective in communicating research findings based on three of the four evaluation criteria used: it generates more questions and emotion among audience members and influences a greater number of individuals to alter their initial understanding of and opinion on an issue. The Café scientifique and the artistic performance both help participants to better understand the topic examined. The arts, however, shine a different light on the issue.
\end{abstract}

Keywords: Arts-Based Research; Café Scientifique; Evaluation; Health Research; Knowledge Dissemination; Performed Research

\section{Introduction}

The Canadian Institutes of Health Research (CIHR), the major funding agency for health research in Canada, has dedicated significant effort to improving the effectiveness of public outreach and knowledge dissemination activities across the country. Indeed, knowledge dissemination and public outreach constitutes one of the four areas of CIHR's Citizen Engagement Framework, a strategy aimed at "realizing a more systematic, ongoing integration of citizens' input in priority setting, governance and funding programs and tools” (Venuta \& Graham, 2010: p. 216). To support their action plan, the CIHR introduced, among other initiatives, the Café Scientifique program. This initiative provides funding to scientific investigators to organize public discussions of their work. It is a way of engaging scientists and the public in open dialogue in a non-academic setting where participants can enjoy a beer, glass of wine, or cup of coffee (Dallas, 2006). The Café Scientifique is intended as an "opportunity to bring together researchers with members of the public to spark a discussion about some of the most interesting - and sometimes contentious-research currently underway in Canada" (CIHR, 2007: p. 3). Initially launched in Leeds, UK in 1998 following the French Cafés Philosophiques model (Dallas, 1999), the concept has since caught on and cafés have been held all over the world (Davies et al., 2009). More than 330 Cafés Scientifiques have been sponsored by CIHR since the program was initiated in 2007. This represents close to one million dollars in funding if applicants receive the base budget of \$3000 (CAD) to organize each individual Café.

The arts have also emerged in the last few years as an innovative method for communicating with the Canadian public about health-related matters (Cox et al., 2010). Initially used in research for representation and dissemination of findings, arts-based methods are now employed in all stages of inquiry (Fraser \& Sayah, 2011): as a stimulus for data generation, a method for eliciting meanings and values, an intervention tool or a form of dissemination (Bergum \& Godkin, 2008). A wide range of artistic forms are utilized by Canadian arts-based researchers: dance (Boydell et al., 2011); poetry (Groft \& Robinson-Vollman, 2007; Lapum, 2005); theatrical performances (Cox et al., 2009a; Colantino et al., 2008; McIntyre \& Cole, 2008; Clarke \& Nisker, 2007; Doucet et al., 2007; Kontos \& Naglie, 2007; Eakin \& Endicott, 2006; Mitchell et al., 2006; Nisker et al., 2006; Sinding et al., 2006; Gray et al., 2000; Ivonoffski \& Gray, 2000); visuals (Poudrier \& MacLean, 2009, Castleden \& Garvin, 2008; Oliffe \& Botorff, 2007; Moffitt \& Robinson-Vollman, 2004); and a combination of various forms of art (Cox et al., 2009b; Lafrenière \& Cox, 2010).

Some (Haines, 2010, Knowles \& Cole, 2008) argue that the empathic understanding generated by arts-based methods can provide deep insight into what others are experiencing. Some experiences may not be possible to articulate in ordinary discourse and could remain virtually unknown through traditional research methods (O’Donoghue, 2007). Arts-based methods may be especially effective in knowledge translation as they open scholarly work to a larger community and provide a stimulus to dialogue (Nisker et al., 2006). It has been argued that inequalities in the distribution of knowledge impacts health disparities (Viswanath \& Emmons, 2009). Forty-eight percent of the Canadian adults cannot read or can read only simple language. Not surprisingly, most belong to the socioeconomiccally disadvantaged populations (Rootman \& Ronson, 2005). The arts could assist in providing information in an accessible form. Arts-based researchers also claim that artistic means of knowledge dissemination engage more effectively the imagination and emotions in the act of understanding experiences, problems and practices (Eisner, 2008a, 2008b; Rossiter et al., 2008; Cahnmann, 2008). This generates emotional as well as intellectual engagement with the issues presented (Mienczakowski, 2009), may foster critical awareness, encourage audiences to 
envision new possibilities, and affect change.

CIHR has funded 22 arts-based research projects since 2008 for a total amount of \$4,075,887 (CAD). This is encouraging but remains a small portion of CIHR's annual grants and awards budget (of roughly $\$ 930$ million (CAD)). However, as the field matures methodologically and theoretically, and a larger body of evidence demonstrates its effectiveness, it is likely that more researchers in health and other science based disciplines will begin infusing the arts into their research.

\section{Case Study}

Centring the Human Subject in Health Research: Understanding the Meaning and Experience of Research Participation $^{1}$ is a three-phase project designed to further understanding of the experiences of human subjects participating in a wide range of health research (McDonald \& Cox, 2009; McDonald et al., 2008). The goals of the project were to gain insight into the subjects' experiences of being a research participant, and focusing on the human subject's perspective in particular, we sought to compare and contrast their perspectives with the perspectives of researchers, research workers and members of research ethics boards. Participants in various types of health research studies (i.e., clinical trials, behavioural, biomedical or public health studies) were interviewed about their experiences of participating in specific studies and asked to comment on what being a human subject means to them. Our knowledge dissemination plan encompassed several strategies including the Café scientifique as well as the combined use of various artistic forms (including drama, "found" poetry, song and visual art).

In this article, we compare the effectiveness of a Café Scientifique and an artistic performance, two knowledge disseminationn interventions that aimed at communicating research findings from the Centring the Human Subject study.

\section{Methods}

\section{Café Scientifique}

Our Café scientifique entitled Volunteers for health research: guinea pigs or partners? was held on May 11, 2009 in Vancouver, Canada. The structure of our Café was similar to any other with the exception that we included a formal evaluation component with the approval of the UBC Research Ethics Board. First, the facilitator (Co-PI M McDonald) introduced the topic and the objectives of the Café. Then, three panelists each offered a ten-minute oral presentation, without any visual aids, on their perspectives on being a human subject in health research. The first panelist talked about his personal experience of being both a participant in health studies and a patient advocacy activist. Then, two other presenters from our research team (PI S. Cox and Co-Investigator J. Kaufert) reported on selected results that emerged from the Centring the Human Subject project.

One of the Café presenters (Cox) commented on four themes: trust between human subjects and research workers, costs/burdens for human subjects of participating in health research, reasons

\footnotetext{
${ }^{1}$ Centring the Human Subject in Health Research: Understanding the Meaning and Experience of Research Participation is a five-year research project funded by the Canadian Institutes of Health Research. Susan M. Cox, Principal Investigator; Michael McDonald, Co-Principal Investigator; Patricia Kaufert, Joseph Kaufert, and Anne Townsend, Co-Investigators. The study is a two-site project at the University of British Columbia (UBC) and the University of Manitoba.
}

for participating in health studies, and relationships between human subjects and research workers. The other speaker (Kaufert) described salient issues of community relationships in health studies explaining the risks and benefits to individuals and ethnocultural or Indigenous communities. He took the perspectives of the workers who mediate the relationship with the research participants.

After the three formal presentations, members of the audience were invited (by Lafrenière) to complete the first section of the survey that was distributed upon arrival. They were given 10 minutes to complete this section which had four open-ended questions about the effects of the presentations on understanding of the topic, specific emotions generated, questions arising, and prompts leading to altered understanding of or opinions about research participation. The facilitator then launched a fifty-minute dialogue that was followed by a draw for two \$25 gift certificates intended to encourage continued participation in the event. Audience members were then asked to complete the second part of the survey dealing exclusively with the discussion period.

Thirty-seven participants filled-out our paper and pencilbased survey (Table 1). Close to two-thirds of the survey respondents were women. One third were aged between 30 and 39 years. A quarter were between 40 and 49 . A majority of the respondents identified themselves as being part of a research community (i.e. researchers, research workers, research ethics board members, research participants, policy-makers, funding agency members, etc.) and more than half indicated that they were also members of the general public. Just over one third of the participants said that they were exclusively members of the general public.

\section{Artistic Performance}

Our pilot project, Designing, Implementing and Assessing Arts-Based Methods of Knowledge Translation in Research Ethics, was part of the dissemination strategy for Centring the Human Subject, and constituted an experiment in the use of arts-based methods. ${ }^{2}$

To achieve this, we first collaborated with artists to create works in one of four artistic forms- "found" poetry, drama, song, or visual arts-from selected portions of transcripts from the Centring the Human Subject study. The four types of artistic media used the same portions of thematically coded interview transcripts and hence were based upon the same set of substantive ideas and experiences. The relevant themes (which were also covered by the second panelist in the Café présentation) were:

1) Reasons for participating (e.g. seeking access to better treatment);

2) Costs/burdens of participating (e.g. missing time at work);

3) Relationships (e.g. sensitivity shown by a researcher), and;

4) Trust (e.g. in research institutions).

The pilot project was conducted over an 18-month period, involved more than 50 artist-collaborators, amateur and professsional, produced 39 poems, two songs, four visuals, and one theatre play. A graduate student who had extensive experience as a theatre practitioner acted as our artistic director and put together the artistic performance from a selection of the artistic

\footnotetext{
${ }^{2}$ We received a small grant from the UBC Humanities and Social Science (HSS) Research Fund/College for Interdisciplinary Studies HSS Research Grants (\#17R72572) - (7000 \$ CAD) to conduct the pilot-project.
} 
Table 1.

Profile of respondents.

\begin{tabular}{|c|c|c|}
\hline Characteristics & $\begin{array}{c}\text { Café } \\
\text { Scientifique }\end{array}$ & $\begin{array}{c}\text { Artistic } \\
\text { performances (2) }\end{array}$ \\
\hline \multicolumn{3}{|l|}{ Gender } \\
\hline - Female & 22 & 33 \\
\hline - Male & 11 & 7 \\
\hline - $\quad$ Not specified & 4 & 1 \\
\hline \multicolumn{3}{|l|}{ Age } \\
\hline - $20-29$ yrs & 4 & 5 \\
\hline - $\quad 30-39$ yrs & 12 & 11 \\
\hline - $40-49$ yrs & 9 & 8 \\
\hline - $50-59$ yrs & 5 & 8 \\
\hline - $60-69$ yrs & 2 & 6 \\
\hline - $\quad 70$ yrs and over & 2 & 1 \\
\hline - $\quad$ Not specified & 3 & 2 \\
\hline \multicolumn{3}{|l|}{ Role } \\
\hline - Funding agency member & 1 & 0 \\
\hline - General public & 20 & 11 \\
\hline - General public & 1 & 0 \\
\hline - $\quad$ Patient organization member & 1 & 0 \\
\hline $\begin{array}{l}\text { - } \quad \text { Policy-maker } \\
\text { - }\end{array}$ & 9 & 18 \\
\hline - Research Ethics Board member & 2 & 3 \\
\hline - $\quad$ Research worker & 6 & 6 \\
\hline - Scholar & 3 & 10 \\
\hline - $\quad$ Other & 4 & 10 \\
\hline - $\quad$ Not specified & 4 & 0 \\
\hline
\end{tabular}

works created. The performance unfolded as follows:

1) Introductory remarks about the research project and ethical aspects (Cox);

2) Commencement to situate the broader study and arts-based project (with all the artists involved in the production);

3) Thematic theatre scene on trust;

4) Song, featuring also a tango dance;

5) Recitation of three poems about trust and practical costs;

6) Thematic theatre scene on practical costs;

7) Song about practical costs;

8) Recitation of three poems about practical costs, relationships and reasons for participating in health research;

9) Thematic theatre scene on reasons for participating;

10) Recitation of three poems on relationships and trust;

11) Re-commencement (with all the artists involved in the production).

The final production of approximately 40 minutes was performed twice for two very different audiences: participants in the research, and members of the University and wider community. Both events took place in Vancouver in November 2009.

Following each performance, members of the audience were invited (by Lafrenière) to complete the first section of a survey provided upon arrival. This section of the survey assessed the effects of the artistic performance on individual audience members in the same way as the Café Scientifique. We then launched a dialogue between the audience members, the artists and the research team. This conversation lasted about 50 minutes and followed a fairly traditional question and answer format. Audience members were then asked to complete the second part of the survey dealing exclusively with the impact of the dialogue on the same four criteria mentioned above. The same questions were asked in the Café Scientifique and the artistic performance survey. Approximately 70 people attended one of the two artistic performances and 41 completed the survey (Lafrenière \& Cox, 2010).

Eighty percent $(80 \%)$ of the survey respondents were women (Table 1). Close to $20 \%$ were aged over 60 years. Most of the respondents identified themselves as being part of a research community (i.e. researchers, research workers, research ethics board members, research participants, funding agency members, etc.). Slightly over a quarter of the respondents indicated that they were members of the general public.

Participants in both events (i.e., Café Scientifique and artistic performance) were recruited using a similar approach. We posted flyers at strategic locations in Vancouver, sent emails through relevant listserves and spread the word among colleagues and relatives. We published an ad in a local newspaper to advertize the Café. Attendance at the first presentation of the artistic performance was restricted to the participants in the Centring the Human Subject study. We took advantage of the fact that we were organizing a two-day-and-a-half workshop on the use of arts-based methods in health research to present the artistic performance a second time the following day during a portion of the workshop that was open to the public.

\section{Results}

How effective are the Café Scientifique and the artistic performance for conveying study results? Here we report on the results from four questions asked to the respondents in the open-ended survey.

1) Did the presentations from the panelists (Café Scientifique) or the artistic performance (arts-based event) help you understand the experiences of research participants enrolled in health-related studies? Explain briefly.

2) Did the presentations from the panelists (Café Scientifique) or the artistic performance (arts-based event) generate emotions/feelings in you? Explain briefly.

3) Did the presentations from the panelists (Café Scientifique) or the artistic performance (arts-based event) raise questions that were so intriguing or important that you would like to engage in further discussion about it? Give some examples.

4) Did the presentations from the panelists (Café Scientifique) or the artistic performance (arts-based event) and the conversa- tion that followed between the panelists (Café Scientifique) or the artists and the researchers (arts-based event) move you to change in some ways your opinion or your initial understanding of the way research participants experience health research? Explain briefly.

\section{Café Scientifique}

\section{Understanding of Research Participation}

A majority of participants (31/37) felt that the presentations contributed to their understanding of the topic. However, only a few respondents could provide specific examples of elements they better understood following the presentations by panelists. This is something that a participant learned from the Café presentations.

The participants are in a trust relationship with the researchers. It [research participation] can involve a great deal of time off work (female, general public, 60 - 69 years old).

Approximately one third of the respondents stated that the presentations had a limited effect or no effect at all in helping them understand the experiences of research participants.

Slightly. No information or case studies that were surprising (male, scholar, 60 - 69 years old). 
Some indicated that the information presented did not go into sufficient detail. Others said it was too basic. One of our panelists was a participant in health related studies, as well as a patient advocacy group member. Although two panelist researchers were also reporting on the lived-experience of individuals who participated in health related studies, audience members were particularly interested to hear the speech delivered by the research participant on the panel:

It was good to hear the viewpoint of the volunteer [panelist] first hand and speak of the motivations, benefits and risks of volunteering in research studies (female, general public, 30 - 39 years old).

Interestingly, a fair number of participants mentioned that they gained a better understanding about topics that were not specifically covered by the presenters. Those topics, such as vulnerable populations, conflict of interest, or consent forms, were brought forward by audience members during the discussion period.

\section{Creating Emotions among Audience Members}

Six different emotions were identified by nine respondents in the Café: anger, empathy, empowerment, frustration, guilt, and pride. Empathy was the emotion most commonly reported, as shown by one of the participants who felt empathy towards the panelist who was member of a patient advocacy group. Most of the emotions that were reported were in relation to the presentation of this panelist.

To participate as a research participant can be especially emotionally rewarding as described by the individual participating in arthritis research. I can now see the need to want to give something back after receiving the benefits of science in treating one's chronic arthritis (male, general public, 50 - 59 years old).

A few audience members explained that the presentations resonated with their own experiences, and thus that they could relate to what was expressed by presenters.

I could relate to the volunteer's emotion of trusting the researchers and the process of research while also being a bit hesitant and frustrated with not receiving enough information or data at the end of the study (female, general public, 30 - 39 years old).

However, most of the participants said that they did not feel any particular emotion while listening to the presentations.

\section{Raising Questions}

The respondents were invited to identify questions raised for them by the presentations. Most of the answers obtained referred to comments rather than to questions: "Mistrust is very crucial in the topic of health research" (no demographic information provided by respondent). When questions were indeed identified by participants, they were for most part very general in their content.

I would like to know more about consumer patient advocacy groups (female, research facilitator, 30 - 39 years old).

Some of the questions that were identified by the respondents in the survey had no direct connection with the presentations of the panelists. They referred for instance to conflict of interest in research, funding priorities in health research, the power of the research ethics boards (institutional review boards), the differrences between various research designs.

\section{Moving to Change Opinions and Initial Understanding}

Two audience members reported that the presentations and the subsequent discussion changed their opinion or their initial understanding of the nature of the relationships between researchers and research participants.

I was very impressed with the depth of concern for [research] subjects by medical researchers. This was not my impression before attending the presentation (male, general public, 40 - 49 years old).

A few individuals mentioned that the Café made them think a little bit more about aspects of the volunteer experience in health research: "It gave me a lot to ponder" (female, general public, 40 - 49 years old). However, most of the respondents said that the presentations and the following conversation did not change their thinking about the topics discussed during the evening.

Some audience members also commented on the overall format. The following participant response suggests that the discussion period after the panelists' presentations did not raise additional and/or valuable information, as it was not focused on the topic covered by the Café.

The initial presentation [panel] was more informative. Questions and comments seemed to go off on a tangent or many different tangents depending on who was speaking (female, funding agency member/patient organization member, 40 - 49 years old).

\section{Artistic Performance}

\section{Understanding of Research Participation}

Responses to the survey revealed that the artistic production allowed for a deeper understanding of the realities of human subjects' participation in health research. None of the respondents mentioned that the artistic performance did not help them understand these experiences. Interestingly, in general, the responses to the survey were far more complete and extensive in the case of the artistic performance than of the Café Scientifique.

I understood that the consent process is confusing and silencing. It brings up questions regarding informed consent. I also better understood the imposition some aspects of the research is on a participant (e.g., taking time off work, urinating into a measure). Participants are not treated with the respect they deserve (e.g., [absence of] thank you notes-even for those who leave the study (Female, researcher, scholar, research participant, 30 - 39 years old).

Some respondents claimed that the media that were used impacted their understanding. The artistic representation of the information allowed them to understand differently the experiences of the human subjects.

One example that stands out for me (as someone who obtains informed consents from vulnerable participants) was the dance, the tango that made me think of how the researcher needs to be seductive to convince participants. Very evocative, and without watching that performance, I 
would not have thought of it that way" (female, researcher, 40 - 49 years old).

It seems that because the artistic media that we used personalized participation in research, it also helped some respondents to understand differently research participants' experiences.

Poetry readers-as if hearing the research participants speaking allows for a way to sense that they are real people and not just the "file numbers" that the "system" uses (Female, scholar, 30 - 39 years old).

For others, the artistic performance allowed them to understand the complexity of the emotions felt by the research participants.

Yes, the gap between inner doubt and resistance on one side, and compliance with authority on the other (Male, scholar, 60 - 69 years old).

Still others picked out the capacity of arts to create a unique type of understanding.

Usually, this kind of understanding is achieved only when one talks to participants personally, where body language, situational, casual speech really convey how someone feels. As second-hand explanation of someone else's experience, this is more effective than a textual document in really conveying the emotion of a clinical patient (Female, research participant, 20 - 29 years old).

\section{Creating Emotions among Audience Members}

The performance created 15 different types of emotion (e.g., empathy, guilt, sadness) among 38 of the 41 respondents to the survey. As with the Café Scientifique, empathy is the emotion that was the most commonly felt. It was the case among more of one third of the audience members. However, more often than not, several emotions were felt at the same time.

I felt upset with myself for all the studies I've done where I didn't disseminate findings to the subjects or thank them appropriately. I felt protective of the subject who was given drugs and a urine collector. I wanted to speak out for her (female, researcher, scholar, research participant, 30 - 39 years old).

We can feel that the respondents were engaged and that the intensity of emotions was palpable in the artistic performance.

I felt angry, helpless and frustrated. When one subject wondered to herself all the questions she has... but is unable to ask the clinician. It seemed to capture for me the frustrations of the "institutional" structure of clinical trials (Female, researcher and scholar, 30 - 39 years old).

For more than one third of the respondents, the artistic performance brought them back to their own experiences, which were often painful and loaded with emotions.

As I am a research participant in clinical trials for metastatic cancer, feelings around lack of choice and helplessness were strong for me during the performance i.e., I have taken a drug that quite possibly was harming me, but it was the better of two options - the other being death. This put me in a position as a research participant of feeling compromised and unsafe. This was well conveyed by the performers (Female, general public, patient, research participant, 30 - 39 years old).

\section{Raising Questions}

The artistic performance generated almost five times more questions than the presentations in the Café Scientifique. The questions pertained to the content, as in the next quotes wherein a respondent refers to two poems that were recited during the arts-based production.

Yes, especially “Trust” and "Vital Statistics”. Without trust the system of health related studies could not exist. It is hard for patients to understand statistics used by the physicians. How to make it understandable for the human subject? (female, research worker, 30 - 39 years old).

Other respondents wondered about the media that were used.

What are the implications of interpretation of subjective experience? How much empathy is required to really experience another's experience... which medium is the most effective at expressing each case of subject matter? (Female, researcher, 30 - 39 years old).

Still others were concerned about the impact that Understanding the Human Subject study will have in the medical community and the general public.

The most important question is how this research is going to affect/change the medical profession's attitudes, and possibly get to a wider audience so that the public/subjects feel more empowered and able to question (Female, general public, 60 - 69 years old).

How do we take the experiences and needs of the human subjects and incorporate them into our system? How do we ensure our system is responsive and addressing the actual concerns of those engaged as subjects? (Female, researcher, 30 - 39 years old).

\section{Moving to Change Opinions and Initial Understanding}

Eight respondents reported that the viewing of the artistic performance would alter their professional practice.

All performances [artistic pieces] generated feelings - for me as a research scientist, feeling strongly that I will be different in my RA's [research assistant] approach to consenting and explaining research (Female, researcher, research ethics board member, 50 - 59 years old).

A respondent mentioned that her opinion about the lived experience of her relatives changed after attending the artistic performance.

I further realized how my experience in the healthcare system resonates with others. I feel I can relate further to family and friends who express frustration when treated as an unfeeling "subject” (female, scholar, 30 - 39 years old).

\section{Discussion}

Laswell's communication model (Lasswell, 1948) identifies the five major components of a communication transmission process. Who says what in what channel to whom with what effect? Although very simple, Lasswell's formula, developed at the end of the 1940s, inspired Lavis and colleagues (2003) who came up with a similar organizing framework designed for use by researchers when planning knowledge dissemination strate- 
gies. What should be transferred to decision-makers? To whom should it be transferred? By whom should research knowledge be transferred? How should research knowledge be transferred? With what effect should research knowledge be transferred? We will refer to these five common elements-communicator, message, media, audience, effect-in the analysis of our case study.

\section{The "Communicator" ("Who")}

It is worth pointing out that audience members attributed a high level of credibility to the one panelist in the Café who was representative of a patients advocacy group and who was also a health research participant. This does not mean that the other presenters were contested or that their expertise was challenged -not at all-but elements of the presentation of the non-researcher panelist were clearly at the forefront of the responses in the surveys, as if they weighed more. Yet, the researcherpanelists were also the voice of the research participants in our study. They were reporting on the accounts of the interviews conducted within the Centring on the Human Subject project. If credibility is a measure of perceived trustworthiness combined with perceived expertness of a source (Hovland \& Weiss, 1952), we could suggest, then, that experiential expertise communicated first-hand attracts greater attention from audience members than more analytical descriptions of an experience delivered by intermediaries, no matter how trustworthy and competent.

Also, one must know that sharing one's own experience generates a more emotional response, in particular empathy, as this act is linked to a positive verisimilitude assessment by the audience (Boyd III, 2006). This is without the fact that the health research participant panelist was an out-spoken individual, very talented at communication. He delivered his presentation with great enthusiasm, a loud tone and confidence, which also probably contributed to increase audience member warms feelings towards his talk (Thomas \& Soldow, 1989). Again, this is not to diminish the quality of the delivery performed by the other speakers, but just to highlight that the effect of his presentation on the audience members was enhanced by his personal style.

Issues pertaining to the messenger are totally different in the case of the artistic performance. The idea of the artist as the messenger was not challenged by anyone who responded to the survey. However, some respondents questioned the various layers of interpretations that are inevitable in an artistic performance. Those questions are legitimate if one considers that the human subjects told the story about their experiences during the research interview, the researchers coded the transcripts according to what they believed were emerging themes, the artists used the thematic transcript excerpts provided to them and selected the portions that "talked to them the most" to create their artistic works, and the audience members made sense of the information that they received based on their own experience, beliefs, values, etc. Clearly the human subjects, the researchers, the artists, and the audience members all engage in varying levels of interpretation.

Given these numerous layers of interpretation, one could challenge the validity of the représentations of the research data that were being disseminated (Eisner, 1981). Indeed, some survey respondents pointed out that the negative experiences of the research participants were featured more predominantly than the positive ones. However, the resonance with the audience members of the situations presented in the artistic performance were such that we cannot doubt the validity of the research data that was communicated. Close to one third of the respondents, without being invited to do it, spontaneously described how the situations expressed in the artistic performance were similar to the ones that they themselves lived, were currently living, or that some of their relatives were living. Interestingly, only two such comments came from participants in the Centring the Human Subject study. This is particularly significant because the perceived relevance of the study results by the audience members is a decisive factor in the uptake of new knowledge and practice change (Kontos \& Naglie, 2007).

\section{The Audience ("Whom")}

The Canadian Institutes of Health Research's Café Scientifique program aims at reaching "the general public". What seems clear is that there were not a significant number of attendees at our Café that were "true members of the general public", if by this we mean, as CIHR does, people who have an interest in the topic being discussed but who are not particularly knowledgeable about it (Kurath \& Gisler, 2009). Most of the participants to the event were people concerned by the topic discussed: researchers, research workers, ethics board members, research participants, etc. Thus, if, in theory, the general public is targetted by the promoters of the Cafés Scientifiques, in practice, it seems that audiences are mainly composed of individuals from the same community of practice. On a continuum, the public that attended our Café would be positioned between the stakeholders, if we define this term as "parties that have a "stake" (self-interest in terms of resources, power, etc.) in a given issue" (Abelson et al., 2007: p. 7) and the "individuals from the general public" as previously described. Participants were more "affected individuals", if we refer to CIHR's typology, which is to say that attendees were individuals personally affected by the issue who can speak to their own experiences, perspectives and ideas rather than represent the viewpoints of any organization with which they may or may not be affiliated (http://www.cihr-irsc.gc.ca/e/41288.html\#s2a1). The same comments are worth noting for the artistic performance. Most of the participants were also "affected individuals". However, it is important to specify that almost one third of the audience members who completed the survey during the artistic performance were also participants in an international workshop on the use of arts-based methods in health research. This must be seen as a limitation in our study. We cannot ascertain that the fact that the artistic performance was largely seen as an effective knowledge dissemination intervention is unrelated to the composition of the audience. The individuals who attended the workshop, upon invitation, undoubtably had an interest in arts-based methods and it is most likely that they had a positive opinion about this innovative mode of dissemination. However, these individuals were also fully aware that this field of research is nascent, and that rigourous theoretical and methodological development is essential to gain broader acceptance, credibility and respect in the research community and beyond. For this reason, we trust that our respondents provided honest answers to the survey questions.

\section{The Message ("What")}

Even if most of the attendees to our Café were familiar with the domain of health research, the message that was communi- 
cated did not satisfy everyone equally. Some would have liked more explanations about our research findings. Others thought that the information provided was too basic for their level of knowledge. It becomes difficult for the Cafés' organizers to tailor their message to a specific audience as there is no such thing as a "general public", as explained above. Thus, we suggest that organizers would benefit from adapting their message to a more knowledgeable audience than that promoted by the CIHR, since attendees are mostly "affected individuals".

There is more to be said about the message. For Marshall McLuhan (1964), the medium is the message. A photograph classified in an album will not have the same effect and will not convey the same message to the individual who is looking at it as the same picture hanging on a wall in a museum. We tend to support this assertion. The structure of the answers to the survey, as well as the terminology that was used to complete it, were very different in the Café and in the artistic performance. Yet, the themes that were covered by each medium were the same, and the questions on the survey were identical.

It seems that the message acts in synergy with the form chosen to convey the information. The content that was delivered with a more analytical form (Café Scientifique) generated answers that were more factual and concise. When expressed artistically (artistic performance), the message engendered written reactions that were generally longer and laden with emotions. Little (2009) would probably explain this "phenomenon" by the close relationship that exists between aesthetics and ethics. Thus, the artistic media would have the capacity to provoke both aesthetic judgement and moral judgement. As a consequence, one should not be surprised to read excerpts of respondents' responses to our survey who, emotionally stimulated by the artistic performance, enter into some sort of ethical reflection, and indicate, for instance if they are researchers, that they feel guilty for not having provided their research participants with the study results, or not having taken enough time to carefully explain the research protocol during the informed consent process. Some respondents accused researchers of treating research participants as objects, of not showing respect to them, etc. These moral judgements were absent from the responses to the survey completed during the Café Scientifique.

\section{The Media ("Channel”)}

Dearing \& Kreuter (2010) claim that knowledge dissemination differs from knowledge diffusion in that the former involves creating and providing access to information, and the latter is about engaging in a social process to resolve uncertainty about adopting a new information, innovation, program, etc. According to these descriptions, we could assert that the Cafés Scientifiques are structured to include both of these two processes. First, the information is disseminated by the speakers (a "push approach"). Subsequently attendees have the opportunity to engage in a discussion with other members of the audience and the presenters to make up their mind about the information provided, by listening, talking, asking questions (a "pull approach"). They will then decide if they adopt the information, reject it or search for more details from other sources.

Interestingly, respondents were divided as to whether the conversation between the presenters and the audience members, and the discussion between members of the audience, helped their understanding of the topic. Some thought that questions and comments were tangential to the main topic. This is probably one of the main difficulties that we experienced with the format of the Cafés Scientifiques. Attendees have different needs and motivations for participating in this type of event (Michael, 2009). In our specific case, some participants had their own agenda and tried to push it during the discussion. Others were seeking advice (i.e. what do other researchers understand by "risks/benefits" in a consent form?). Some wished to voice their community's concerns (i.e. claimed that the needs of vulnerable communities are not understood as they should be and that their interests are not part of funding priorities), or to learn more about a specific issue (i.e. monetary payment of human subjects' contribution to research). Since the objective of the Cafés is to favour discussion in an atmosphere that is not too formal, it is not always easy to bring back the conversation to the main topic. In this context, effectiveness of the diffusion process within the Cafés is thus far less predictable than the effectiveness of the dissemination process.

We did not experience the same situation with the artistic performance. The attendees remained focused on the content of the production during the post-performance conversation. They were also shrouded by the emotions generated by the arts-based presentation.

\section{The Effect (“Effect”)}

Our goal in comparing two modes of knowledge dissemination interventions is not to establish the superiority of one over the other. We are fully aware that the assessment criteria that were used for comparing the two media were taken from the literature on arts as a research method. If we had selected criteria more adapted to oral presentations such as in Cafés Scientifiques, conferences or symposiums, the results on effectiveness probably would have been different. For instance, the Cafés Scientifiques are promoted for their capacity to democratize scientific debates. Participants attending these events have the opportunity to ask questions and talk about their concerns pertaining to scientific developments (Bauer, 2009). Organizers can thus hardly direct the discussions as the very concept of the Cafés implies that the participants attend these events to express themselves and not merely to obtain information. They are the ones who lead the conversation on what is of interest to them about the topic. In this regard, the artistic performances leave less space for participants to determine what they want to discuss. There is a greater focus on themes the researchers want to cover. As a consequence, if the flexibility regarding the discussions post-performance (arts) or post-presentations (Cafés) had been identified as one criteria of effectiveness, the Café would have probably obtained better results than the artistic performance.

Overall findings from our survey suggest that the effectiveness of the Café Scientifique as means of conveying study results is similar to more traditional methods of knowledge dissemination in that the panelists and audience discussion seemed to foster intellectual understanding. We did not find evidence that the Café Scientifique format offers a novel method of knowledge dissemination when compared to other alternatives such as arts-based methods which appeal to the emotion as well as the intellect, and seem to be also more effective for generating questions and moving people to change their opinions, attitudes and even practice.

In light of our experience in holding a Café and an artistic performance, we conclude that: 
- Communicator. Experiential knowledge delivered firsthand by talented communicators has more effect on the audience than knowledge reported by intermediaries even if they are competent about the subject and good communicators. There are several communicators in an artistic performance. The research participants, the researchers and the artists are all involved in the creation of the end-product.

- Audience. Most attendees at knowledge dissemination interventions open to the general public have at least a general knowledge of the topic discussed and/or are personally affected by the issues.

- Message. Messages to be conveyed in Cafés Scientifiques should thus be tailored to audience members with a general knowledge of the topic.

- Media. Cafés scientifiques encompass both dissemination processes and diffusion processes. Given the objective behind the Cafés, the effectiveness of the diffusion process is less predictable.

- Effect. The artistic performance is more effective than the Café scientifique organized in the traditional way (a few short presentations without visual aid, facilitated by an MC, followed by a discussion period) in communicating research findings based on three of the four evaluation criteria used: it triggers more emotions among audience members, generates more questions on the topic discussed, and influences a greater number of individuals to alter their opinion and initial understanding of an issue. The Café Scientifique and the artistic performance both help participants to better understand the topic examined. The arts, however, shine a different light on the issue.

\section{Acknowledgements}

During the course of this work, Darquise Lafrenière was supported by a Canadian Institutes of Health Research (CIHR) fellowship (Ethics of Health Research and Policy Training Programme).

\section{REFERENCES}

Abelson, J., Giacomini, M., Lehoux, P., \& Gauvin, F. P. (2007). Bringing "the Public" into health technology assessment and coverage policy decisions: From principles to practice. Health Policy, 82, 37-50. doi:10.1016/j.healthpol.2006.07.009

Bauer, M. W. (2009). Editorial. Public Understanding of Science, 18, 378-382. doi:10.1177/0963662509340123

Bergum, V., \& Godkin, D. (2008). Nursing research and the transformative value of art. In G. J. Knowles, \& A. L. Cole (Eds.), Handbook of the arts in qualitative research: Perspectives, methodologies, examples and issues (pp. 603-612). Los Angeles: Sages Publications.

Boyd III, H. C. (2006). Persuasive talk: Is it what you say or how you say it? Journal of Advertising Research, 46, 84-92. doi:10.2501/S0021849906060090

Boydell, K. M., Jackson, S., \& Strauss, J. S. (2011). Help seeking experiences of youth with first episode psychosis: A research-based dance production. In K. M. Boydell, \& H. B. Ferguson (Eds.), Hearing voices: Qualitative inquiry in early psychosis. Waterloo, ON: Wilfrid Laurier Press.

Cahnmann-Taylor, M. (2008). Arts-based-research: Histories and new directions. In M. Cahnmann-Taylor, \& R. Siegesmund (Eds.), Artsbased research in education-Foundations for practice (pp. 3-15). New York and London: Routledge.

Canadian Institutes of Health Research. (2007). CIHR Café Scientifique: Guidelines for Organizers. URL.

http://www.cihr-irsc.gc.ca/e/documents/ca_cafescieniifiqueOrganizer
sJan25-07_e.pdf

Castleden, H., Garvin, T., \& Huu-ay-aht First Nation. (2008). Modifying photovoice for community-based participatory Indigenous research. Social Science and Medicine, 66, 1393-1405. doi:10.1016/j.socscimed.2007.11.030

Clarke, L. E., \& Nisker, J. (2007). In our hands: On becoming a doctor. Lawrencetown Beach, NS: Pottersfield Press.

Colantonio, A., Kontos, P. C., Gilbert, J. E., Rossiter, K., Gray, J., \& Keightley, M. L. (2008). After the crash: Research-based theater for knowledge transfer. The Journal for Continuing Education in Health Professions, 28, 180-185. doi:10.1002/chp.177

Cole, A., \& Knowles, G. J., (2010). Arts-informed research. In G. J. Knowles, \& A. L. Cole (Eds.), Handbook of the arts in qualitative research: Perspectives, methodologies, examples and issues (pp. 55-81). Los Angeles: Sages Publications.

Cox, S. M., Lafrenière, D., Brett-McLean, P., Collie, K., Cooley, N., Dunbrack, J., \& Frager, G. (2010). Tipping the iceberg? The state of arts and health in Canada. Arts \& Health, 2, 109-124.

Cox, S. M., Kazubowski-Houston, M., \& Nisker, J. (2009a). Genetics on stage: Theatre and public engagement in health policy development. Social Science and Medicine, 68, 1472-1480. doi:10.1016/j.socscimed.2009.01.044

Cox, S. M., Lafrenière, D., Belliveau, G., Lea, G. W., O’Donoghue, D., \& Sharon, R. (2009b). Centring the human subject. Disseminating study results through drama, poetry, song and visual arts [DVD]. Vancouver: SFU Media Design Services.

Dallas, D. (2006). Café scientifique—Déjà vu. Cell, 126, 227-229. doi:10.1016/j.cell.2006.07.006

Dallas, D. (1999). The café scientifique. Nature, 399, 120. doi:10.1038/20118

Davies, S., McCallie, E., Simonsson, E., Lehr, J., \& Duensing, S. (2009). Discussing dialogue: Perspectives on the value of science dialogue events that do not inform policy. Public Understanding of Science, 18, 338-353. doi:10.1177/0963662507079760

Deuring, J. W., \& Kreuter, M. W. (2010). Designing for diffusion: How can we improve uptake of cancer communication innovations? $\mathrm{Pa}$ tient Education and Counseling, 81, S100-S110. doi:10.1016/j.pec.2010.10.013

Doucet, H., Dion-Labrie, M., Durand, C., \& Ganache, I. (2007). Genomics and modes of democratic dialogue: An analysis of two projects. In B. M. Knopper (Ed.), Genomics and public health: Legal and socio-ethical perspectives (pp. 287-304). Leiden/Boston: Martinus Nijhoff.

Eakin, K., \& Endicott, M. (2006). Knowledge Translation through Research-Based Theatre. Healthcare Policy/Politiques de santé, 2, 54-59.

Eisner, E. (2008a). Art and knowledge. In G. J. Knowles, \& A. L. Cole (Eds.), Handbook of the arts in qualitative research: Perspectives, methodologies, examples and issues (pp. 3-12). Los Angeles: Sages Publications.

Eisner, E. (2008b). Persistent tensions in arts-based research. In M. Cahnmann-Taylor, \& R. Siegesmund (Eds.), Arts-based research in education-Foundations for practice (pp. 16-27). New York and London: Routledge.

Eisner, E. (1981). On the difference between scientific and artistic approaches to qualitative research. Educational Researchers, 10, 5-9.

Fraser, K. D., \& Sayah, F. (2011). Arts-based Methods in Health Research: A Systematic Review of the Literature. Arts \& Health, 3, 110-145.

Gray, R. E., Sinding, C., Ivonoffski, V., Fitch, M., Hampton, A., \& Greenberg, M. (2000). The use of research-based theatre in a project related to metastatic breast cancer. Health Expectations, 3, 137-144. doi:10.1046/j.1369-6513.2000.00071.x

Groft J. N., \& Robinson Vollman, A. (2007). Seeking serenity: Living with HIV/AIDS in rural Western Canada. Rural and Remote Health, 7, 677.

Haines, R., Oliffe, J. L., \& Botorff, J. L., Poland, J. L., \& Blake, D. (2010). "The missing picture": Tobacco use through the eyes of smokers. Tobacco Control, 19, 206-212. doi:10.1136/tc.2008.027565

Hovland, C., \& Weiss, W. (1952). The influence of source credibility in communication effectiveness. Public Opinion Quarterly, 15, 635-650. doi:10.1086/266350 


\section{LAFRENIERE ET AL.}

Ivonoffski, V., \& Gray, R. E. (2000). No big deal? Toronto, ON: Toronto Sunnybrook Regional Centre.

Kontos, P., \& Naglie, G. (2007). "Expressions of personhood in Alzheimer's disease": An evaluation of research-based theatre as a pedagogical tool. Qualitative Health Research, 17, 799-811. doi:10.1177/1049732307302838

Kurath, M., \& Gisler, P. (2009). Informing, involving or engaging? Science communication, in the Ages of Atom-, Bio- and Nanotechnology. Public Understanding of Science, 18, 559-573. doi:10.1177/0963662509104723

Lafrenière, D., \& Cox, S. M. (2010). Comparaison de deux méthodes de dissémination de résultats de recherche dans le domaine de la santé: Les arts et le café scientifique. Sociologie et sociétés, 42, 121142.

Lapum, J. (2005). Women's Experiences of Heart Surgery Recovery: A Poetical Dissemination. Canadian Journal of Cardiovascular Nursing, 15, 12-20.

Lasswell, H. D. (1948). The structure and function of communication in society. In L. Bryson (Ed.), The communication of ideas (pp. 37-51). New York: Harper and Row.

Lavis, J. N., Robertson, D., Woodside, J. M., McLeod, C. B., \& Abelson, J. (2003). How can research organizations more effectively transfer research knowledge to decision makers? Milbank Quarterly, 81, 221-248. doi:10.1111/1468-0009.t01-1-00052

Little, J. M. (2010). Is there a real nexus between ethics and aesthetics? Bioethical Inquiry, 7, 91-102. doi:10.1007/s11673-010-9214-x

McDonald, M., \& Cox, S. M. (2009). Moving towards evidence-based human participant protection. Journal of Academic Ethics, 7, 1-16. doi:10.1007/s10805-009-9082-3

McDonald, M., Townsend, A., Cox, S.M., Damiano Paterson, N., \& Lafrenière, D. (2008). Accounts of human subjects: Optimizing trust in health research relationships. Journal of Empirical Research on Human Research Ethics, 3, 35-47. doi:10.1525/jer.2008.3.4.35

McIntyre, M., \& Cole, A. (2008). Love stories about caregiving and Alzheimer's disease-A Performative methodology. Journal of Health Psychology, 13, 213-225. doi:10.1177/1359105307086701

McLuhan, M. (1964). Understanding media: The extensions of man. New York: McGraw Hill.

Michael, M. (2009). Publics performing publics: Of PiGs, PiPs and politics. Public Understanding of Science, 18, 617-631. doi:10.1177/0963662508098581

Mienczakowski, J. (2009). Pretending to know: Ethnography, artistry and audience. Ethnography and Education, 4, 321-333. doi:10.1080/17457820903170127

Mitchell, G. J., Jonas-Simpson, C. M., and Ivonoffski, V. (2006). Research-based theatre: The making of I'm still here! Nursing Science Quarterly, 19, 198-206. doi:10.1177/0894318406289878

Moffit, P., \& Vollman, A. R. (2004). Photovoice: Picturing the health of Aboriginal women in a remote northern community. Canadian Journal of Nursing Research, 36, 189-201.

Nisker, J. A., Martin, D., Bluhm, R., \& Daar, A. (2006). Theatre as a public engagement tool for health-policy research. Health Policy, 78, 258-271. doi:10.1016/j.healthpol.2005.10.009

O’Donoghue, D. (2007). “James always hangs out here”: Making space for place in studying masculinities at school. Visual Studies, 22, 62-73. doi:10.1080/14725860601167218

Oliffe, J. L., \& Botorff, J. L. (2007). Further than the eye can see: Photo ellicitation and research with men. Qualitative Health Research, 17, 850-858. doi:10.1177/1049732306298756

Poudrier, J., \& MacLean, R. T. (2009). "We've fallen into the cracks": Aboriginal women's experiences with breast cancer through photovoice. Nursing Inquiry, 16, 306-317. doi:10.1111/j.1440-1800.2009.00435.x

Rootman, I., \& Ronson, B. (2005). Literacy and health research in canada: where have we been and where should we go? Canadian Journal of Public Health, 96, 62-77.

Rossiter, K., Kontos, P., Colantonio, A., Gilbert, J., Gray, J., \& Keightley, M. (2008). Staging data: Theatre as tool for analysis and knowledge transfer in health research. Social Science \& Medicine, 66, 130-146. doi:10.1016/j.socscimed.2007.07.021

Sinding, C., Gray, R., Grassau, P., Damianakis, F., \& Hampson, A. (2006). Audience responses to a research-based drama about life after breast cancer. Psycho-Oncology, 15, 694-700. doi:10.1002/pon.998

Thomas, G. P., \& Soldow, G. F. (1989). Nonverbal behavior in television advertising: How forceful is a forceful actor? In J. H. Leigh, \& C. R. Martin Jr. (Eds.), Current Issues and Research in Advertising, Ann Arbor, MI: University of Michigan Graduate School of Business Administration.

Venuta, R., \& Graham, I. D. (2010). Involving citizens and patients in health research. Journal of Ambulatory Care Management, 33, 215222.

Viswanath, K., \& Emmons, K. (2006), Message effects and social determinants of health: Its application to cancer disparities. Journal of Communication, 56, S238-S264. doi:10.1111/j.1460-2466.2006.00292.x 